ISSN 1989 - 9572

DOI: 10.47750/jett.2020.11.01.001

\title{
Formation of foreign language professionally oriented competence of future foreign language teachers with the use of electronic educational resources
}

Yevheniia M. Provorova ${ }^{1}$

Tetiana O. Harasym ${ }^{2}$ Andriana R. Zubryk ${ }^{3}$ Olha V. Ladyka ${ }^{4}$ Valentyna A. Shepitchak ${ }^{5}$

\section{Journal for Educators, Teachers and Trainers, Vol. 11 (1)}

https://jett.labosfor.com/

Date of reception: 15 March 2020

Date of revision: 12 June 2020

Date of acceptance: 18 August 2020

Yevheniia M. Provorova, Tetiana O. Harasym, Andriana R. Zubryk, Olha V. Ladyka \& Valentyna A. Shepitchak (2020). Formation of foreign language professionally oriented competence of future foreign language teachers with the use of electronic educational resources. Journal for Educators, Teachers and Trainers, Vol. 11(1). 1 - 12.

${ }^{1}$ Department of Theory and Methods of Voice Production, Anatolii Avdiievsky Faculty of Arts, National Pedagogical Dragomanov University, Ukraine

2,3,4,5 Department of English Philology and English Language Teaching Methods, Faculty of Foreign Languages, Ternopil Volodymyr Hnatiuk National Pedagogical University, Ternopil, Ukraine 


\title{
Journal for Educators, Teachers and Trainers, Vol. 11 (1)
}

\author{
ISSN 1989 - 9572 \\ https://jett.labosfor.com/
}

\section{Formation of foreign language professionally oriented competence of future foreign language teachers with the use of electronic educational resources.} Yevheniia M. Provorova ${ }^{1}$, Tetiana O. Harasym ${ }^{2}$, Andriana R. Zubryk ${ }^{3}$, Olha V. Ladyka ${ }^{4}$, Valentyna A. Shepitchak ${ }^{5}$

${ }^{1}$ Department of Theory and Methods of Voice Production, Anatolii Avdiievsky Faculty of Arts, National Pedagogical Dragomanov University, Ukraine

2,3,4,5 Department of English Philology and English Language Teaching Methods, Faculty of Foreign Languages, Ternopil Volodymyr Hnatiuk National Pedagogical University, Ternopil, Ukraine

Email ID: E.provorova@gmail.com, tetyana_harasym@gmail.com, andriazubryk@gmail.com, olga.ladyka@tnpu.edu.ua, valia.myskiv@gmail.com

\begin{abstract}
The study tested electronic educational resources recommended and selected for development of language competencies in future teachers. Motivational, cognitive and communicative criteria were chosen as indicators of professional readiness. The research involved relevant methods and forms of improving language competencies and diagnostic methods. Meanwhile the level of the development of professional competencies was monitored with reasonable adjustment of students' independent work. The choice of electronic educational resources as the main tool of independent work improves the linguistic communicative competencies of students, activates their search, learning and selforganization; motivates to create their own educational trajectory, and improves the academic performance. The use of electronic resources is not an independent technology for teachers' training; it requires implementation in the educational process. The effectiveness of these methods of organizing the educational process is $25 \%$ of the quantitative composition of the experimental groups, so the subject of the study requires development and implementation in the educational field. The effectiveness of application of the results determines practical value of this article. The offered methods can be applied to students majoring in the Humanities, and in independent language study. This research can be used for development of programs and courses in independent, distance and differentiated learning.
\end{abstract}

Keywords: Linguodidactics, Foreign Language Competence, E-learning, Cloud Technologies, Independent Work, Personal Educational Trajectory.

\section{INTRODUCTION}

The total digitalization and informatization of all spheres of public life currently requires a revision of traditional approaches and methods of education as one of the most important forms of social consciousness. The educational sector provides staffing of the future society, so it must meet all the latest requirements and challenges of the time. On the other hand, along with the latest communication technologies, language proficiency remains an important factor in personal and corporate international communication. We can argue on this basis that electronic means of communication and learning foreign languages are important factors of personal, group and social progress. Foreign language and information (technological) competencies are equally relevant in the organization of full-fledged communication, so they need constant updating and following the 
requirements of the time. They are mutually determined and are most often used in the same spheres of activity and public consciousness. Therefore, it is natural to unite them within a single educational process.

In light of the above, the use of electronic educational resources in the development of students majoring in Foreign Languages - teachers, translators, diplomats, etc. seems urgent. The first link in this list is the teacher as the initial subject of the development of an individual capable of effective communication. Therefore, the key issue is the problem of training foreign language teachers in current information and communication environment.

Since the 1990's, methodologists in all developed countries have used electronic resources to train foreign language teachers in order to mutually enhance the effectiveness of electronic and foreign language communication (Kultusministerkonferenz, 2017; Wache, 2003). In the 2000's, digital technologies acquired a separate independent status - up to "e-learning". The latter is gradually becoming a separate form of education, along with correspondence, full-time and distance learning. Classical approaches are, however, still relevant in the countries of the former Commonwealth of Independent States: the lecture-seminar system of education, the discreteness of socionic subjects, as well as the importance of the teacher as the main source of didactic information. These facts require a radical transformation of higher education in the region, and hence the relevant methodological developments and generalizations. Ukraine, as a developing democratic state which chooses a pro-European vector of the development, is interesting, on the one hand, with its classical educational traditions and, on the other one, in the long transitional educational processes. In this regard, the study on the introduction of e-learning methods is of particular interest because students, according to surveys, spontaneously use electronic resources. It can be hypothesized that the implementation of certain forms of e-learning of foreign languages (only as a resource component) will have unexpected results in higher educational institutions in Ukraine.

In Western Europe, this methodological problem is solved. Higher education there is able to preserve the traditions of classical universities, and fully comply with the latest information and technological trends. We agree with the opinion of German experts in e-learning that it has the following practically oriented features: a) flexibility (learning time, place, method, duration, content and methods); b) simplicity of presentation of complex phenomena and objects through visualization, animation and simulation; c) motivation of educational activity by attractive design of multimedia games and presentations; d) resourcefulness (dictionaries, lexicons, glossaries, references); e) focus on teamwork in the context of new network communication (Kultusministerkonferenz, 2017; Bock, 2018). These prospects require independence and high motivation of students, as well as the transformation of the directive full-time education into distance supervised one. The latter provides an emphasis on independent types of educational activities, which, together with the specifics of the use of electronic educational resources, are the subject of this study.

In Western Europe, teaching foreign language competence through electronic resources is not only becoming important in linguodidactics, but also becomes its centre, philosophical principle and the most effective tool. It symbolizes continuity, versatility and accessibility; becomes a new paradigm of education in the Humanities (Gilakjani, 2017). This study is an experimental attempt to make e-learning the core of self-training of future foreign language teachers. Students of the experimental groups easily agreed to reorient their studies towards independence. Unfortunately, this is due to the fact that students of selected universities believe that self-study is easier and frees up time for their own affairs. Therefore, the prospect of its full implementation requires a change in motivation and the transformation of the classical opposition "student - teacher" into cooperation on equal terms, and the synergistic effect of such cooperation.

Online courses in the Humanities have become increasingly popular in Western European universities. Such courses are an open multifunctional electronic resource (Lorenz, 2018, p.28). At the same time, students of distance online courses show a high level of engagement, motivation, while the process and results of their training are significantly different from traditional ones. They have just started to apply this practice in higher educational institutions of the post-Soviet republics, which adds topicality to this study.

German experts in e-learning resources note that the dissemination and application of ER in the educational process is largely the responsibility of pupils and students. The level of their responsibility should be controlled by the tools of constant monitoring of the quality of education and take into account the cultural and social specifics of the region (Zawacki-Richter \& Mayrberger, 2017, p.7-8). In our study, the emphasis is on monitoring 
the independent preparation of students, and the cultural and social specifics of the use of ER require a separate study.

German experts in e-learning resources note that the dissemination and application of ER in the educational process is largely the responsibility of pupils and students. The level of their responsibility should be controlled by the tools of constant monitoring of the quality of education and take into account the cultural and social specifics of the region (Zawacki-Richter \& Mayrberger, 2017, p.7-8). In our study the emphasis is on monitoring the independent preparation of students and the cultural and social specifics of the use of ER require a separate study.

The above scientific provisions are taken into account in the modelling, implementation and analysis of the initial data of the formative-diagnostic experiment to improve the foreign language professionally oriented competence of future foreign language teachers through the use of electronic educational resources.

\section{MATERIALS AND METHODS}

The study of optimizing the development of foreign language professionally oriented competence of future foreign language teachers with the help of electronic educational resources was conducted during the 2018-2019 academic year on the basis of foreign language faculties of the National Pedagogical Dragomanov University, Anatolii Avdiievsky Faculty of Arts (Kyiv), and Ternopil Volodymyr Hnatiuk National Pedagogical University, Faculty of Foreign Languages (Ternopil).

The research involved the second-year undergraduate students studying the main subjects for this stage: Practical Course of the Main Language (English) and Practical Course of the Second Language (German). The experiment involved a total of 114 people ( 2 control and 2 experimental groups). Outside the experiment, we conducted a survey of the second-fourth-year students to determine priorities in the use of foreign language skills when working with gadgets (see Table 1). These previously obtained results were taken into account during the formation of the optional base of electronic educational and non-educational resources, which were provided to the participants of the experiment.

The objective of the study was to test and verify the effectiveness of the scientific hypothesis. The latter was that the cognitive, motivational sphere of an individual and language-communicative competence of future foreign language teachers should increase with the change of educational conditions, namely - providing maximum access and freedom of choice of electronic learning resources, as well as independent planning and implementation of educational activities supervised by teachers Donaghue (2015). These competence groups were selected as the most valid in terms of performance with smart technologies (Bauer, 2005). Selforganization, ability to self-study and use of non-educational resources (first of all, cultural and mass media content) were also subjected to diagnosis.

The methods of diagnostics of changing competencies were written testing, oral interview, comparison of initial and final academic performance of control and experimental groups. The results of the current control of the acquisition of professional competencies by the EG participants were taken into account in supervision and adjustment of independent work. The starting principle was the secondary role of the teacher (mentor, supervisor, tutor etc.) in the development of foreign language competence. This is due to the generally accepted fact: according to the studies, the teacher's role is no longer universal and decisive, so it implies a high motivation, responsibility and independence of students as subjects of the educational process (Zlatea \& Cucui, 2014; Heift \& Schulze, 2015).

In this regard, it was decided to give EG students the maximum freedom to choose electronic resources to achieve the didactic objectives during the formative and summative assessment according to the objectives of the study. This stage involved the following: a) a list of mandatory electronic resources is provided; b) a list of optional resources is provided; c) it is allowed to choose an unlimited number of resources independently for the purpose of self-formation of personal educational environment and personal educational trajectory. The students independently recorded the dynamics and quality of self-formed environment and trajectory in their personal diary.

During the formative stage of the experiment, the number of in-class sessions was reduced, and the method of conducting them was reoriented from translational-directive to supervisory-communicative. The CG students used only the first two groups of electronic resources (compulsory and optional, Figure 1, and continued to study according to the classic system for domestic higher educational institutions in the format of lectures - seminars - 
laboratory sessions. Specific competence learning outcomes were clearly defined for control groups, and for experimental groups - by $60 \%$ only (professional competencies). The time and assignments for independent work were extended for the EG students. The emphasis was on self-study with maintaining a notebook of personal educational trajectory and control through tests and interviews.

\section{THE COURSE OF THE EXPERIMENT}

Before the start of the empirical stage of the experiment, two academic groups were randomly selected from the four available in the second-year of the Institute of Foreign Languages. Members of the experimental groups were informed about participating in the experiment. Participants in the other two academic groups studied according to the standard curriculum and were not informed about participating in the experiment as control groups. We did it for the sake of "purity" of the experiment and the naturalness of the academic performance achieved by the control groups. The final competencies of the EG participants were compared with these results. The latter, after 2 introductory lectures, was offered to independently study the material in Practical Course of the Main Language (English) and Practical Course of the Second Language (German), and emphasized the importance of electronic resources as the main didactic material. This is followed by a list of mandatory electronic resources and an open list of optional ones. It is proposed to supplement this list with individually selected electronic resources and didactic software during the first four weeks of study. The educational process was realized in the form of supervision and reporting. Both tutorials and current control had individual and group forms of organization of the educational process according to the principle of "group mandatory - group optional - individual mandatory." After students adapted to the new educational environment, they were asked to independently plan in-class sessions, study with the use of selected software and electronic resources, and visit the teacher as needed (tutorials), with the mandatory passage of current control and module tests.

At the beginning of the experiment, the author analysed the methodological resources and the opportunities they provide, compiled a classification scheme of electronic resources, which is relevant to our study (Figure 1). After entering the experiment (up to 4 weeks), the EG students were presented with the following scheme and asked to choose the priority type of learning (leftmost column) and supplement the electronic resources found by themselves (rightmost column).

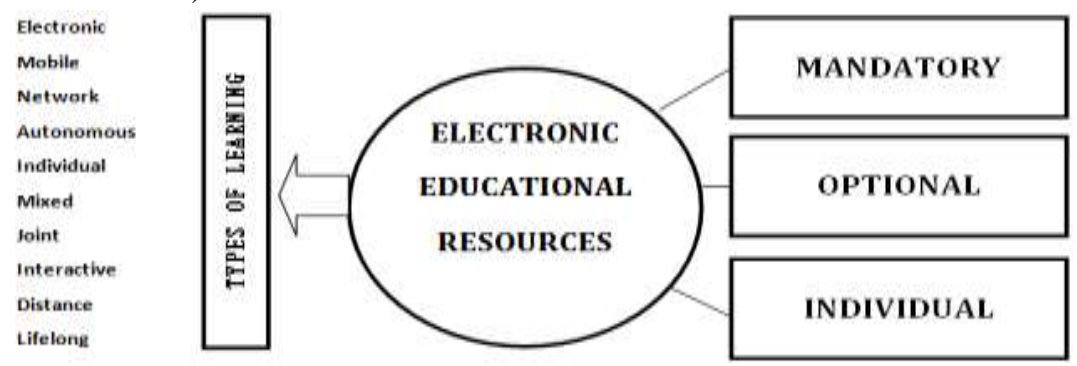

Figure 1: Types of electronic educational resources and their connection with learning

According to the scheme, the EG students were offered virtually all types of ER for independent selection and creating their own educational trajectory. Alternative forms of education - first of all, individual, distance, network and mobile - were also proposed within a differentiated individual plan. They were used as comprehensively as possible, and were reflected in the individual diary of the EG participants.

The control of the dynamics of the formative experiment in EG was carried out in accordance with modern approaches to the monitoring of educational activities. According to these approaches, monitoring of educational activities can be considered in a broader (monitoring of education) and narrower (monitoring of educational activities) sense. Modern education monitoring specialists note that during the experimental implementation of new educational content or during the normal educational process, monitoring allows observing and recording the dynamics of the development of program competencies. This is in line with the framework provisions on the application of monitoring in the Humanities. Thus, the approach used in the study correlates with the provisions of the Law of Ukraine "On Education", where internal and external monitoring is defined as the main tool for control and self-diagnosis of the subjects of the educational process. Three-stage control (at the beginning, at the intermediate and final stage of the experiment), which was also used in the study, proved the effectiveness of the approaches proposed in the works of modern methodologists (Mishra, 2005; Mertens, 2009). 
Since learning in a cloud environment involves minimal off-line communication between the subjects of educational interaction, it is especially important to establish feedback. The regularity of this communication is the main (along with the predicted competencies and current reports) obligatory component of experimental selflearning in the practice of English and German: students had the opportunity not to come for tutorials, but attended diagnostic classes and had online communication with the teacher on a weekly basis.

The problem of experimental assessment of the quality of education in the Humanities is the impossibility to delineate the boundaries of the predicted knowledge, as well as to identify and evaluate them in a specific semantic or numerical form. In this regard, it was decided in parallel with the use of tests, listening exercises, etc. to introduce knowledge control through interviews. In this regard, it was decided to introduce knowledge control through interviews in parallel with the use of tests, listening exercises, etc. The latter allows outlining the foreign language "outlook" of the student, although it has signs of subjectivity in its assessment. The list of topics identified by students of control and experimental groups was expanded in this way. The main teachers' requirement to their own control activities was to provide assessment data in the most detailed form. The increase in the students' vocabulary was diagnosed by maintaining a diary of their individual educational trajectory and comparing its content with oral speech; expanding the foreign language picture of the world - by interviewing on extracurricular topics (more than 80 of them were identified). Such concretization of the results of the acquisition of competencies in the Humanities correlates with the requirements for concreteness and clarity during the current and final monitoring of knowledge (Noh, 2006).

The results of the experiment, represented as initial and final scores according to selected criteria, were subject to mathematical calculation with identification of the dynamics of academic performance (arithmetic mean for groups in the range high - mean - low levels in control and experimental groups). Only final results of educational activity of control groups were taken for comparison, and intermediate results of control groups were used for adjustment of independent work and creating a personal educational trajectory.

\section{LITERATURE REVIEW}

The research is based on methodological approaches used in modern linguodidactic discourse. We can agree with the statement in Bock (2018) about the onset of a total transformation of traditional learning in the period of the "digital revolution of textbooks." The author believes that the didactic text on paper slows down the development, so it is subject to continuous digitalization and a new approach to the production and application of didactic material. Based on this study, digital educational media and digital educational programs deserve special attention among Open Educational Resources (OER). Students can choose electronic programs at will. This approach is in line with current trends in Ukrainian higher education: students use the Internet mainly as a database, rather than a repository of functions and programs.

Researchers distinguish the most common types of digital educational resources, such as presentation forms, means of presenting the content of education, learning in social media and free educational resources. The methodological discourse mainly refers to the ER as the main means of independent study of foreign languages (Murray, 2014). These provisions were taken into account in the formation of the classification scheme of electronic resources and their educational potential (see Figure 1). Means of presenting the content of education and programs for the operation and transformation of this content were considered as secondary. Electronic resources as databases were considered primary resources.

The methodological approach, in which a personal educational trajectory within the educational space or environment (personal learning environment) is formed for each student, is valid for application in the study. This environment is formed by both teacher and students. The latter are actively involved in the selection of personal smart tools to improve their professional competence (Barhate \& Narale, 2015, p.38-41; Castañeda, Dabbagh \& Torres-Kompen, 2017; Koper, 2014, p.1-17; Lee, 2015, p.149-155). If the phenomenon of educational space is relatively constant, the trajectory assumes movement and upward dynamics, which was tested in a subsequent experiment. In it, the students had to independently select individual electronic resources and maintain personal educational trajectory.

It seems appropriate to use the concept of "academic self-efficacy", which is used in modern English-language didactic discourse (Sachitra \& Bandara, 2017). This effectiveness depends on many factors: age, gender, level of knowledge, motivation, and so on. In this study, the emphasis is on the motivational aspects of independent application of ER in building a personal educational environment (Benson \& Voller, 2014). This aspect is 
especially applicable to higher education in Ukraine, where teachers traditionally "lead" the student in accordance with a single approved curriculum.

Concretizing the content of a personal educational environment, researchers note: the environment includes didactic official institutions and services, as well as personal self-regulated path of an individual before the acquisition of competencies. The main resource is one's own motivation and activity in selecting and working with electronic resources. An important skill is the student's ability to combine the material and tools obtained in class with the independently formed ones, and develop the need to learn independently throughout life (Castañeda, Dabbagh \& Torres-Kompen, 2017) These provisions provide for the gradual abandonment of stereotypes, according to which one can "get an education": the latter is a permanent process and provides for a constant conformity of the subject to the changing environment.

A number of European scholars (Meurers \& Dickinson, 2017) define cloud technologies as an object of general pedagogical research (limits, objectives and opportunities). These works can serve as a basis for the use of electronic resources in the teaching of any discipline. Instead, electronic resources as the main tool of linguodidactics have repeatedly become the object of scientific research in various aspects: authentication, openness and accessibility of educational technologies (Lorenz, 2018; Lee, 2015), flexibility and universality of "smart learning" using cloud technologies (Barhate \& Narale, 2015, p.38-41; Zhu, Yu \& Riezebos, 2016). The didactic opportunities of electronic resources in the preparation of students of foreign language faculties in modern Ukraine still need, however, a comprehensive analysis and guidelines.

Methodists specialized in teaching foreign languages proved the effectiveness of the use of electronic resources to increase motivation, restructure the content of education, expand methodological tools and bring the educational process closer to modern information and communication realities. A significant advantage of such technologies is the high sensitivity and students' knowledge about the capabilities of the Internet and computer technology (Ahmadi, 2018). We agree that, in addition to the above general advantages, the implementation of "cloud didactics" stimulates the following aspects of improving foreign language competence: speed of access to information, feedback, flexibility in the selection of methods and materials, learning and self-learning, multichannel information (graphics, audio-, video and text resources) (Goyal, 2017; Siddiqui et al., 2019).

Based on the literature analysed above, we believe that the training of foreign language specialists by means of electronic technologies and resources is impossible without reliance on independent work (the teacher does not work directively, but performs the functions of a supervisor and moderator). This presupposition allows narrowing the research topic to self-study and self-acquisition of professional competencies by future foreign language teachers with the help of electronic resources. Learning foreign languages with the use of electronic (cloud) technologies is always differentiated, based on the student's independent work and involves constant recording of student feedback within the "teacher - language - assignment" triad. This connection is mutual, and its means, as well as the main source of knowledge, is the Web. Against this background, group forms of learning lose their advantage and remain valid only for the improvement of communicative competencies.

We agree with the ambiguous approach pointing out the positive and negative aspects of e-learning (Wache, 2003). Despite the difficulty of tracking the "electronic" activities and activities of the subjects of the educational process, the scholar substantiated the universality of the ER for professional and private mastery of economic, socionic fields of practice and that of the humanities. Negative aspects are the complexity of regular control of educational activities, significant differentiation of selected resources and departure from the formation of key professional competencies towards personal prerogatives.

\section{RESULTS}

Industry standard for Bachelor's degree in Speciality 014 Secondary Education, subject specialization - 014.02 Secondary Education (language and literature (English and second foreign language (German)) provides not only the acquisition of language units and methods of teaching, but broad social, cultural and communicative competencies. In this regard, the diagnostic interview with students of control and experimental groups determined the level of communicative ability (on given and free topics), knowledge of the cultural, political and socio-economic realities of English- and German-speaking countries, which corresponds to the concept in Matthew (2015).

The results of this stage of the diagnostic experiment are as follows: 
a) students of control groups communicate $8 \%$ better on compulsory topics; b) students of experimental groups have a much broader communicative outlook; c) students of experimental groups involved $26 \%$ more optional and individually selected electronic resources to their educational environment; d) at the end of the academic year students of experimental groups showed a better vocabulary and flexibility of its use in communicative situations (81 and 76 points, respectively). The latter competence was diagnosed by conducting an interview on 80 sociological and culturological topics, of which only 30 are mandatory according to the curriculum.

As a result of the interview, it was found out that EG students have enough or excellent knowledge of the following topics: Ecology, Pets, HiTec, Computer Games, Social Networks, Communication in the Modern Media Space, Student Professional Prospects, Domestic and World Politics, Tourist Places (Great Britain, USA, Germany, Austria, Switzerland), General and Professional Etiquette, Fashion, Cinema, Music, Design, Creativity, etc. Instead, students in the control groups showed consistent broad knowledge and communication skills on a standard set of topics necessary for successful teaching. Here are the most relevant: representation of oneself, plans for the future, socio-political system and culture of English- and German-speaking countries, everyday life and private life, hobbies and leisure, Ukraine (its history, traditions and culture).

These results show that the formation of cognitive and communicative competencies through independent interaction with the ER has significantly expanded the thematic and lexical range of EG students, but also "blurred" the boundaries of the required areas of communication for a foreign language teacher.

Teachers involved in the experiment subjectively described the difference between experimental and control groups: control groups - academism, consistency, depth, systemacy, professional orientation; experimental groups - flexibility, breadth, superficiality, inconsistency, versatility, modernity. This psychological characteristic corresponds to the semantic aspect of the identified competencies and requires additional research to reduce the level of cognitive entropy in students who study independently with the help of electronic resources. The empirical part of the experiment involved a propaedeutic survey of students of control, experimental and non-experimental groups conducted to determine the rate of independent use of extracurricular resources to improve professional competence. 116 second - fourth-year students were surveyed. The results of the survey are provided in the Table 1.

Table 1: Frequency of use of educational and extracurricular electronic resources

\begin{tabular}{|c|c|c|c|}
\hline Type of resource and its use & $\begin{array}{l}2^{\text {nd }} \text { year } \\
\text { (percentage } \\
\text { of students) }\end{array}$ & $\begin{array}{l}3^{\text {rd }} \text { year } \\
\text { (percentage } \\
\text { of students) }\end{array}$ & $\begin{array}{l}4^{\text {th }} \quad \text { year } \\
\text { (percentage } \\
\text { of students) }\end{array}$ \\
\hline $\begin{array}{l}\text { 1. Social networks (Facebook, Telegram, Instagram, Twitter) } \\
\text { and communication there in a foreign language. } \\
\text { 2. Newspapers, magazines and their electronic versions. } \\
\text { 3. Reading paper and e-books in a foreign language. } \\
\text { 4. Online viewing of films (adapted or original) in a foreign } \\
\text { language. } \\
\text { 5. Search for information on the Internet in a foreign language. } \\
\text { 6. Exchange of information on the Internet (outside social } \\
\text { networks: e-mail, online stores, services, etc.). } \\
\text { 7. Access to specialized lexicographic, didactic, reference or } \\
\text { other Internet resources and databases in a foreign language }\end{array}$ & $\begin{array}{l}95 \\
27 \\
47 \\
35 \\
45 \\
23 \\
34\end{array}$ & $\begin{array}{l}91 \\
34 \\
76 \\
41 \\
56 \\
35 \\
39\end{array}$ & $\begin{array}{l}87 \\
37 \\
83 \\
43 \\
67 \\
40 \\
41\end{array}$ \\
\hline
\end{tabular}

As we can see from the table, the frequency of use of educational and non-educational electronic resources (except for social networks) has a weak upward trend associated with the development of higher didactic requirements for each subsequent course. The results of the survey indicate a low level of self-organization, selfinitiative and self-study at the initial stage of higher education (in this case, $2^{\text {nd }}$ year) and its slow growth. The use of electronic resources without appropriate changes in educational conditions is fragmentary, sporadic and irregular. It is of private entertaining nature and weakly correlates with the development of program competencies.

However, the above data showed the focus of modern students on the pragmatic aspects of foreign language skills: communication, search for useful information, personal interests. The use of this type of motivation to achieve didactic results requires a separate study. 
The results of the formative part of the experiment according to the selected criteria are provided below (see Table 2).

\section{Table 2: Level of the needs and readiness to use ER in the process of the development of professional competencies}

\begin{tabular}{|c|c|c|c|c|c|c|}
\hline \multirow{3}{*}{$\begin{array}{l}\text { Formation } \\
\text { of needs } \\
\text { and } \\
\text { readiness } \\
\text { to use ER }\end{array}$} & \multicolumn{6}{|c|}{ Development levels (\%) } \\
\hline & \multicolumn{3}{|c|}{ Control groups } & \multicolumn{3}{|c|}{ Experimental groups } \\
\hline & $\begin{array}{l}\text { At the } \\
\text { beginning of } \\
\text { the experiment }\end{array}$ & $\begin{array}{l}\text { At the end } \\
\text { of the } \\
\text { experiment }\end{array}$ & Deviation & $\begin{array}{l}\text { At the } \\
\text { beginning of } \\
\text { the experiment }\end{array}$ & $\begin{array}{l}\text { At the end } \\
\text { of the } \\
\text { experiment }\end{array}$ & Deviation \\
\hline \multicolumn{7}{|c|}{ Motivational (self-organizational) criterion } \\
\hline High & 22 & 30 & +8 & 24 & 41 & +17 \\
\hline Medium & 52 & 47 & +3 & 51 & 45 & -6 \\
\hline Low & 26 & 23 & -3 & 12 & 16 & -4 \\
\hline \multicolumn{7}{|c|}{ Cognitive criterion } \\
\hline High & 23 & 34 & +11 & 21 & 36 & +15 \\
\hline Medium & 54 & 51 & -3 & 58 & 50 & -8 \\
\hline Low & 23 & 17 & -6 & 21 & 24 & -3 \\
\hline \multicolumn{7}{|c|}{ Communicative criterion } \\
\hline High & 28 & 31 & +3 & 30 & 40 & +10 \\
\hline Medium & 48 & 50 & +2 & 46 & 49 & +3 \\
\hline Low & 24 & 24 & 0 & 24 & 11 & -13 \\
\hline \multicolumn{7}{|c|}{ Averages for all criteria } \\
\hline High & 24.3 & 31.6 & +7.3 & 28.3 & 39 & +12 \\
\hline Medium & 51.3 & 49.3 & +2 & 51.6 & 48 & -11 \\
\hline Low & 23 & 21.3 & -3 & 19 & 17 & 6.7 \\
\hline
\end{tabular}

As we can see from the final table, the positive dynamics in all three types of competencies is observed only at a high level of training, while medium and low levels show a decrease in performance. The biggest deviation concerns the motivational criterion, which manifests itself in self-organized work with the ER. This indicates a low (22-28\% depending on the selected criterion) willingness to work in a personal cloud environment. This result correlates with the trends of the transitional credit transfer system of education in Ukraine and with the traditions of its higher education. The latter provides that students got used to directive didactics and make little use of the potential of both electronic resources and independent learning. On the other hand, students who were highly motivated to synergistically develop foreign language and information competencies achieved significant success. Hypothetically, we believe that the percentage of such students will grow and e-learning will be gradually transformed from the auxiliary form into the main one.

\section{DISCUSSION}

According to the National Foreign Language Learning and Promotion Initiative (Institute of Education Content Modernization, 2015) and the National Strategy of Education Development in Ukraine for 2012-2021, Ukrainian higher educational institutions are in the process of intensifying and optimizing the study of foreign languages and forming intercultural communication that meets the requirements of the time. This fact adds prospects to the intermediate results of this study. It testifies to the high degree of correlation of language didactic and information technological components, which in synergy should significantly improve the quality of interpersonal and intercultural communication.

The results of the experiment also showed that the development of foreign language professionally oriented competence of future foreign language teachers with the use of electronic educational resources as a basis for independent work of students is a relatively effective and relevant technology. This intermediate conclusion applies to the selected region only and may be invalid for other countries. The relative effectiveness is confirmed by the results of an experiment to modify educational conditions. The use of electronic resources as the main didactic tool not only increases cognitive-communicative professionally oriented competencies, but also increases motivation, responsibility and ability to self-organization and self-learning. In the context of "academic freedom", the EG students found a wide range of thematic interests, expanded their vocabulary and personal 
didactic tools. However, a number of shortcomings of "cloud learning" were revealed, namely: the lack of "live" communication, the difficulty of controlling the current work, excessive individualization of the processed content. These shortcomings are covered in modern e-learning studies (Wache, 2003; Zawacki-Richter \& Mayrberger, 2017).

Despite the wide functionality of computer technology, methodologists emphasize the technological, rather than the educational, function of electronic resources, as proved by the results of the experiment. To transform technology into a didactic technique, it is necessary to restructure the educational environment from traditional to cloud one. Therefore, it is recommended to combine cloud technologies and traditional forms of work, such as the use of paper textbooks, writing an active vocabulary, performing translation exercises with a dictionary, etc. after the experiment. On the other hand, the results of the experiment show that each university academic group has a share of students (on average 25\%) who are able to achieve high results in self-study using electronic educational and non-educational resources.

Based on the obtained data, it became possible to put the concept of building a personal educational trajectory, personal development and management of educational space into practice. These results deepened integrative and information theories of cloud learning (Barhate \& Narale, 2015; Al-Zoube, Abou El-Seoud \& Wyne, 2010; Altun, 2015; Kravtsov \& Gnedkova, 2016), acquisition of foreign language professionally oriented competencies (Ahmadi, 2018), and application of achievements of modern information technologies in education (Afanasieva \& Smyrnova, 2020)

\section{CONCLUSION}

The article clarifies that electronic resources are a promising tool for the modernization of higher education in Ukraine, in particular, increasing the language communication and self-study competence of future foreign language teachers. It is proved that e-learning and application of cloud technologies has become the main approach to the development of professional language competencies in the countries of Western Europe.

Based on the results of the experiment, it is proved that students with high didactic and professional motivation can independently (if necessary - with the advice of teachers) form a personal educational environment through the appropriate selection and independent use of electronic and analogue resources. At the same time, students show positive dynamics in key competencies (Table 2). The full transition to e-learning in the studied region is not yet possible and may be a key, but not the only technological link in the educational process.

The presented theoretical generalizations can become a basis for broader studies in the field of resource-oriented technologies of modern linguodidactics. The research can be the basis for the formation of a complete scientific picture and methodological vision of the following aspects: the role of electronic resources in distance learning, the basics of self-learning of foreign languages, the organization of alternative forms of education, e-learning, etc.

After solving the scientific and methodological problems set in this study, we believe that the use of electronic resources in the study of a foreign language in motivated students causes a mutually reinforcing (synergistic) effect. We consider the gradual implementation of e-learning in Ukrainian universities a promising area. The study allows us to outline the motivational and activity characteristics of student majoring in the Humanities in the selected region. These students need a gradual and controlled transition to electronic resources as the main didactic tools. First, students should work with electronic resources in a computer classroom under the supervision of a teacher. Students will then have to work on the required electronic resources specified by the teacher. Starting from the 2nd year of the Bachelor's degree, students can independently choose electronic educational and extracurricular resources on the basis of guidelines. Successful implementation of such activities will demonstrate the students' ability to create their own educational space and educational strategy.

The theoretical generalizations obtained and methodological testing of electronic resources in the research will have a much greater effect in practice under the conditions of the final transformation of the credit transfer system of higher education in Ukraine. The study made it clear that such a transformation cannot be implemented "from above", but requires the readiness, academic mobility and maturity of Ukrainian students. The reform itself will be possible under the conditions of autonomy and independence of universities, which will be able to independently choose educational strategies.

Based on the obtained results, we consider it necessary to further develop and implement electronic resources in the educational process as the main didactic tool. This requires further research to increase the motivation and 
ability to self-regulation of undergraduate students studying for Bachelor's degree; revision of the content of bachelor's education and general revision of curricula and work programs.

\section{REFERENCES}

1. Afanasieva, L., \& Smyrnova, M. (2020). The usage of the achievements of modern information technologies in education. Scientific Notes of Ostroh Academy National University: Philology Series, 8(76), 123-126.

2. Ahmadi, M. R. (2018). The use of technology in English language learning: A literature review. International Journal of Research in English Education, 3(2), 115-125.

3. Altun, M. (2015). The integration of technology into foreign language teaching. International Journal of New Trends in Education and their Implications, 6(1), 22-27.

4. Al-Zoube, M., Abou El-Seoud, S., \& Wyne, M. F. (2010). Cloud computing based E-learning system. International Journal of Distance Education Technologies (IJDET), 8(2), 58-71.

5. Barhate, S. M., \& Narale, S. (2015). Cloud based teaching and learning environment for smart education. International Journal on Recent and Innovation Trends in Computing and Communication, 3(2), 38-41.

6. Bauer, K.-O. (2005). Pädagogische Basis kompetenzen. Theorie und Training [Basic pedagogical skills. Theory and training]. Juventa.

7. Benson, P., \& Voller, P. (2014). Autonomy and independence in language learning. Routledge.

8. Bock, A. (2018). The Transformation of School Textbooks into Digital Educational Media. Retrieved from http://repository.gei.de/handle/11428/291?show=full.

9. Castañeda, L., Dabbagh, N., \& Torres-Kompen, R. (2017). Personal learning environments: Research-based practices, frameworks and challenges. Journal of New Approaches in Educational Research, 6(1), 1-2.

10. Donaghue, H. (2015). Changing practice and enabling development: The impact of technology on teaching and language teacher education in UAE federal institutions'. In T. S. C. Farrell (Ed.), International Perspectives on English Language Teacher Education (pp.142-159). Palgrave Macmillan.

11. Gilakjani, A. P. (2017). A review of the literature on the integration of technology into the learning and teaching of English language skills. International Journal of English Linguistics, 7(5), 95-106.

12. Goyal, A. (2017). 8 Benefits of Adopting Cloud-Based Applications in Education. E-Learning Industry. Retrieved from https://elearningindustry.com/cloud-based-applications-ineducation-8-benefits.

13. Heift, T., \& Schulze, M. (2015). Tutorial computer-assisted language learning. Language Teaching, 48(4), 471-490.

14. Institute of Education Content Modernization. (2015). Go Global: National Foreign Language Learning and Promotion Initiative. Retrieved from http://www.imzo.gov.ua/wpcontent/uploads/2015/11/Natsionalna-programa-vivchennya-ta-populyarizatsiyi-inozemnihmov-dopovidach-Pavlo-Hobzey.pdf.

15. Koper, R. (2014). Conditions for effective smart learning environments. Smart Learning Environments, 1(1), 1-17.

16. Kravtsov, H., \& Gnedkova, O. (2016). The Use of Cloud Services for Learning Foreign Language (English). International Conference on ICT in Education. Kyiv, Ukraine.

17. Kultusministerkonferenz. (2017). Strategie der Kultusministerkonferenz „Bildung in der digitalen Welt." [The Standing Conference's "Education in the Digital World" strategy]. Retrieved from https://www.kmk.org/themen/bildung-in-der-digitalen-welt/strategiebildung-in-der-digitalen-welt.html

18. Lee, A. (2015). Authentication scheme for smart learning system in the cloud computing environment. Journal of Computer Virology and Hacking Techniques, 11, 149-155. 
19. Lorenz, A. (2018). Eine Offene Bildungs ressource (OER) Ist Konsequent Eingesetzt Eine Chance für Den Hochschulzugang: Ein Praxisbericht [An Open Educational Resource (OER) Is Consistently Used An Opportunity For University Admission: A Practice Report]. Medien Pädagogik: Zeitschrift für Theorie Und Praxis Der Medienbildung, 32, 28-40.

20. Matthew, E. (2015). Sociocultural theory and second language development. In: B. Van Patten, \& J. Williams (eds.), Theories in Second Language Acquisition: An Introduction (pp.207-226). Routledge.

21. Mertens, D. M. (2009). Research and evaluation in education and psychology. 3rd ed. SAGE Publications Inc.

22. Meurers, D., \& Dickinson, M. (2017). Evidence and interpretation in language learning research: opportunities for collaboration with computational linguistics. Language Learning, 67(1), 66-95.

23. Mishra, R. C. (2005). Educational research. A.P.H. Publishing Corporation.

24. Murray, G. (2014). Social dimensions of autonomy in language learning. Palgrave Macmillan.

25. Noh, H. J. (2006). Policy evaluation. 2nd ed. Bupmunsa.

26. Sachitra, V., \& Bandara, U. (2017). Measuring the academic self-efficacy of undergraduates: The role of gender and academic year experience. International Science Index, Educational and Pedagogical Sciences, 11(11), 2443-2448.

27. Siddiqui, S. T., Alam, S., Khan, Z. A., \& Gupta, A. (2019). Cloud-based E-learning: using cloud computing platform for an effective e-learning. In: S. Tiwari, M. Trivedi, K. Mishra, A. Misra, \& K. Kumar (eds.), Smart Innovations in Communication and Computational Sciences. Advances in Intelligent Systems and Computing (pp. 335-346). Springer.

28. Wache, M. (2003). E-Learning - Bildung im digitalen Zeitalter [E-learning - education in the digital age]. Bundeszentrale für politische Bildung.

29. Zawacki-Richter, O., \& Mayrberger, K. (2017). Qualität von OER: Internationale Bestandsaufnahme von Instrumenten zur Qualitätssicherung von Open Educational Resources (OER) - Schritte zue inem deutschen Modell am Beispiel der Hamburg Open Online University [Quality of OER: International inventory of instruments for quality assurance of Open Educational Resources (OER) - steps towards a German model using the example of the Hamburg Open Online University]. Hamburg Open Online University.

30. Zhu, Z.-T., Yu, M.-H., \& Riezebos, P. A. (2016). Research framework of smart education. Smart Learning Environment, 3(1), 1-17.

31. Zlatea, S., \& Cucui, G. (2014). Motivation and performance in higher education. Procedia - Social and Behavioral Sciences, 180, 468-476. 